\title{
Agriculture at the URBAN INTERFAce: Attitudes of New RuRal Residents
}

DANIEL LeVI AND KathrYN SPERRY

Daniel Levi is a

Professor at the

Psychology and Child

Development Department,

Cal Poly San Luis Obispo.

Kathryn Sperry received her B.A. in Psychology from Cal Poly and is a Doctoral candidate in Applied Cognitive

Psychology at Claremont Graduate University.
As the buffer between farming and residential areas shrinks, pesticide related conflicts increase. Dan Levi and Kathryn Sperry discuss their study examining environmental attitudes and health impacts of living at the agricultural / urban interface in Oceano, California. The discussion illustrates the importance of including these potential environmental impacts and their mitigation in the planning agenda.

\section{INTRODUCTION}

\subsection{Urbanization's Effects on Agriculture}

Urban areas are expanding into the surrounding rural countryside, creating development pressure at the urban fringe. This urban expansion into rural areas increases the importance of agricultural preservation. Conserving land for agriculture is valued by residents at the urban fringe, helps preserve the rural economy and helps limit some of the adverse effects of development. Understanding the economic value of agriculture for a city, town or region, as well as its perceived value for the quality of life of the community is one of the main goals for city and regional planning, particularly in the California context.

Surveys show that most Americans (70 percent) prefer a rural or small town setting near an urban area as a place to live (Fuguitt \& Brown, 1990). Improved transportation, information technology and cheaper land values have encouraged people to live outside of urban areas (Johnson, 1999). The highest rate of population growth is on the edges of metropolitan areas, predominately in rural counties.

Farms on the urban fringe are an important segment of U.S. agriculture. These farms produce onethird of the value of agricultural output, while using only 16 percent of U.S. cropland (Heimlich \& Anderson, 2001). Nearby urban areas create new opportunities for farmers, if farmers are willing to make positive adaptations (Johnston \& Bryant, 1987). Farmers adapt to urban pressures of higher property taxes and development pressure by increasing the value of their farm's production and developing marketing techniques oriented toward the urban environment. They shift to "adaptive" farming practices that emphasize higher value crops, more intensive production, new marketing techniques and farm operations that fit an urbanizing environment.

Farming near urban areas has both positive and negative impacts on agriculture. The positive impacts of urbanization include proximity to seasonal labor pool, greater off-farm employment opportunities, new markets for higher value crops - such as fruits and vegetables - and income from recreational activities (horse boarding, U-pick operations, etc.). Negative impacts on farming include complaints from suburban neighbors about farm odors and chemical spraying, conflicts about noise and traffic, reduction of traditional farm markets, higher real estate taxes and pressure on water and land use.

\subsection{Agriculture's Effects on Urban Residents}

Working agricultural lands provides a variety of environmental, economic and social benefits to the neighboring urban communities (CAST, 2002). Agricultural areas provide ecological services, such as storm water management and wastewater reclamation. Agriculture helps with urban planning issues by supporting growth management and providing landscaping and wildlife habitat, while improving air 
quality. The positive economic impacts include providing food, nurseries and greenhouse products, landscaping and animal related businesses. Agriculture also impacts community well-being by maintaining aesthetically pleasing landscapes that provide for social and recreational opportunities, and supporting farmer's markets and community gardens.

Growth at the urban fringe has negative impacts on both the natural environment and rural social system. In some cases, growth can destroy the scenic amenities that attract people to an area (Heimlich \& Anderson, 2001). The loss of open space reduces local recreation and cultural activities. The arrival of new residents and the merging of rural communities with neighboring urban areas can disrupt the sense of community in rural areas. Negative environmental impacts include wildlife habitat destruction, air and water quality problems, consumption of open space and disruption of water runoff.

Conserving the rural lands at the urban fringe is important for both farmers and urban residents. Urban residents derive benefits from agricultural areas for recreation, visual enjoyment and growth reduction. Although urban residents are supportive of farming, they typically are not willing to make sacrifices to support the agricultural sector (Molnar \& Duffy, 1987), and are not willing to accept loss of development opportunities, higher food prices or risk of chemical contamination to sustain nearby agriculture.

As urban areas expand into agricultural areas, the buffer between farm practices and residential areas shrinks and pesticide related conflicts increase. Although rural communities are often familiar with and accepting of the use of agricultural chemicals, urban residents who live near agriculture are less familiar and accepting (Van Driesche et al, 1987). In addition, urban residents moving to rural areas often show higher support for environmental values than existing rural residents (Jones et al, 2003). Pesticide related problems (such as spray drift of pesticides, groundwater contamination and noise and odor problems) could lead to anti-pesticide and anti-agriculture attitudes in the community.

\subsection{Pesticides and Community Health}

Agriculture's use of pesticides can affect surrounding areas through surface and ground water contamination and airborne contamination. Spray drift is the movement of pesticides through the air during application to unintended sites (EPA, 1999). Airborne residues of pesticides can represent a direct hazard to humans, wildlife and vegetation. This hazard is especially evident for people who work in agriculture, but also impacts people who live and work near agricultural areas (NRC, 2000). Although government regulations limit spray drift problems in a variety of ways (i.e., restricting how pesticides are used and training applicators), problems remain and complaints by neighboring residents are increasing.

Off-site movement of pesticides can lead to health problems, both acute (which occur at the time of exposure) and chronic (longer-term) (Arcury, Quandt \& Dearry, 2001). The acute health effects of pesticide exposure include rashes, headaches, nausea and vomiting, and respiratory failure. Longerterm effects of exposure can lead to cancer, neurological problems, and reproductive problems. Chronic health problems are difficult to detect in the early stages, so it is hard to determine the link between health problems and chemical exposure.

Given the relatively low levels of pesticide exposure to people who live adjacent to agricultural areas, the potential impact on human health is uncertain (NRC, 2000). Although research shows that pesticide residues are widely spread throughout urban areas, studies trying to link the use of pesticides with health problems have not been able to demonstrate a direct human health connection 
(Daniels, Olshan, \& Savitz, 1997). Consequently, public concerns about environmental health risks are often focused on unproven or uncertain risks.

Studies show that the public believes that pesticides pose a substantial danger to people, wildlife and the environment through food residues and environmental contamination (NRC, 2000). Beliefs vary widely about how dangerous pesticides are to personal health; however, less than 50 percent of the public believes that the government adequately regulates pesticide use. The growth of the sales of organic produce is one indicator of the public's concerns about food safety. According to surveys in the 1990's, about 70 percent of the pubic support the use of organic agricultural practices.

\subsection{Community-Based Participatory Research}

One approach to dealing with community concerns about environmental health problems is community-based participatory research (CBPR). In CBPR, health professionals and community members cooperatively work to investigate environmental causes of health problems, and develop physical and social approaches to improve community health (Arcury, Quandt, \& Dearry, 2001). This approach uses surveys to gather health information from residents, which is then used by community groups to develop and implement approaches to improving community health.

CBPR is an important approach for dealing with health problems in rural communities that result from environmental causes. This approach has helped document the health disparities resulting from pesticide exposure in agricultural communities. Most of the community-based research in the field of environmental health has examined health impacts on farm workers and evaluation of interventions to reduce workers' pesticide exposure. However, this research approach can be used to examine the health impacts on agricultural communities.

\section{STUDY OUTLINE}

We developed a case study using CPBR to examine environmental attitudes and health impacts of living at the agricultural / urban interface in Oceano, California - an unincorporated town in the San Luis Obispo County, close to the ocean, and with a population of about 7,260 in 2000. To conduct the study, a countywide environmental organization (Environmental Center of San Luis Obispo) partnered with an Oceano community group, researchers at the Center for Latino Health and Culture of UCLA, and faculty and students at the Psychology and Child Development Department of Cal Poly.

The main approach for this research was a community-wide, door-to-door survey conducted by community volunteers and students. The survey examined attitudes about community environmental issues and agriculture, and perceptions of household health. This study provides an example of how CBPR operates and demonstrates community perceptions about living near agriculture.

\subsection{Description of Oceano}

The community of Oceano has several characteristics that are important to understand to interpret the results of the study. Oceano has agricultural fields bordering and within the town. The crops grown in these fields are strawberries and vegetables, and these agricultural areas are substantial users of pesticides and other chemicals.

The town is about a mile from the ocean, with a large area of dunes and agricultural fields in between. These environmental factors can create dust problems and increase problems with pesticide spray 
drift. Because of ground water contamination that may be related to agriculture, the town recently switched from well water to reservoir water. This has lead to complaints about the quality of drinking water in the community.

\subsection{Methods}

The survey was designed to measure perceptions of environmental quality, attitudes toward living near agriculture, household members' perceptions of their health and recollections of specific health problems within the last year. Data on background characteristics of the household was also collected. The surveying was conducted by community and student volunteers, who walked throughout the community of Oceano. The Oceano sample includes data on 1,548 people from 509 households, which represents about one-fifth of the population of Oceano.

\section{RESULTS}

\subsection{Environmental Quality, Attitudes toward Agriculture, and Perceived Health}

Perceptions of environmental quality are summarized in Table 1. These ratings of environmental quality show what the residents like about their environment and help to identify environmental stressors that may be related to perceptions of their health and attitudes about agriculture. Residents had fairly positive perceptions of air quality, traffic and noise in Oceano, but mixed views about the quality of drinking water, amount of pesticides, and dust in the air. Because these variables correlated with each other, an overall perceived environmental quality index was calculated.

The residents were asked to describe what they saw as the main environmental issue affecting their community. Table 2 presents a list of their responses. Mentioned by 25 percent of the residents, agricultural use of pesticides was the most frequently mentioned issue. Other frequently mentioned issues were quality of drinking water, growth and development pressure, increased traffic and congestion, and trash or visual blight.

The residents were asked to rate their attitude about living near agriculture on a scale ranging from a "major benefit" to a "major problem." About half of the residents (53 percent) rated living near agriculture as a benefit, 33 percent were mixed or neutral, and 14 percent viewed living near agriculture as a problem. The participants were asked to describe what they viewed as the major benefit or problem with agriculture. Table 3 shows the responses. The residents listed a variety of benefits of

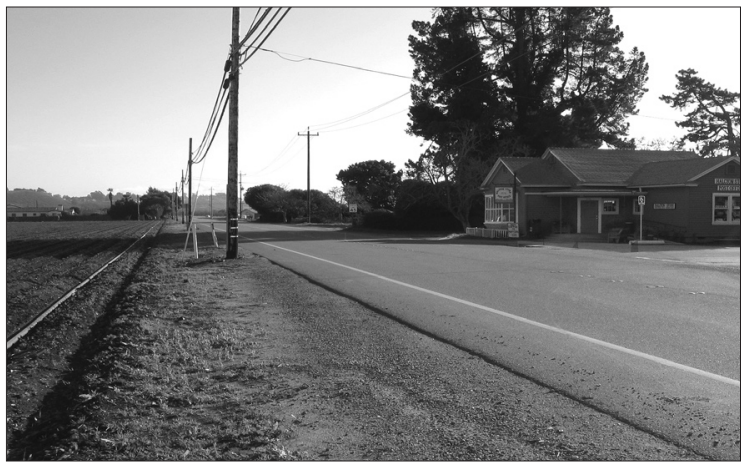

Figure 1

Halcyon Road is a divide between farming and urban uses and homes in Oceano.

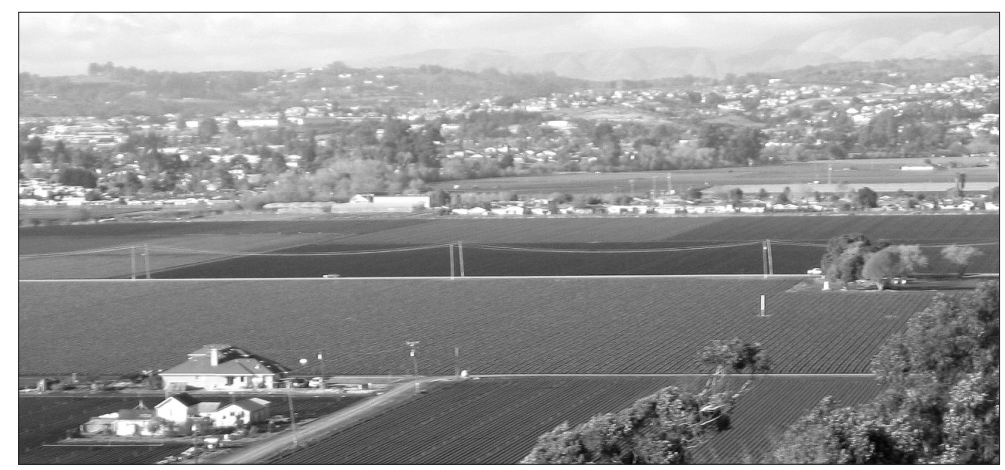

Figure 2

Agricultural area in Oceano showing the proximity of residences and urban Arroyo Grande in the background. 
Table 1: Perceived Environmental Quality Ratings

\begin{tabular}{|l|r|r|l|}
\hline Good & Fair & Poor & \\
\hline $77 \%$ & $17 \%$ & $6 \%$ & Quality of the air \\
\hline $59 \%$ & $26 \%$ & $14 \%$ & Amount of noise \\
\hline $52 \%$ & $25 \%$ & $23 \%$ & Amount of traffic \\
\hline $46 \%$ & $26 \%$ & $28 \%$ & Amount of pesticide use \\
\hline $39 \%$ & $29 \%$ & $32 \%$ & Amount of dust in the air \\
\hline $30 \%$ & $27 \%$ & $43 \%$ & Quality of the drinking water \\
\hline
\end{tabular}

Table 2: Main Environmental Issues Affecting the Community

\begin{tabular}{|c|c|}
\hline $25 \%$ & Agricultural pesticide use and pesticide drift \\
\hline $14 \%$ & Quality of drinking water \\
\hline $13 \%$ & Overpopulation, too much growth, and loss of open space \\
\hline $12 \%$ & Increased traffic and congestion \\
\hline $8 \%$ & Trash, litter, junk cars, and visual blight \\
\hline $6 \%$ & $\begin{array}{l}\text { Infrastructure problems, such as inadequate streetlights, } \\
\text { sidewalks, water drainage, and sewage. }\end{array}$ \\
\hline $6 \%$ & Air pollution, smog, offensive odor, and dust in the air \\
\hline $15 \%$ & Other issues, less than $3 \%$ \\
\hline
\end{tabular}

Table 3: Benefits and Problems of Agriculture

\begin{tabular}{|c|c|l|}
\hline \multirow{4}{*}{ Benefits } & $29 \%$ & Local markets with fresh and cheap food \\
\cline { 2 - 3 } & $18 \%$ & Employment for locals \\
\cline { 2 - 3 } & $16 \%$ & Prevents development and population growth \\
\cline { 2 - 3 } & $16 \%$ & Provides open space and visual beauty \\
\cline { 2 - 3 } & $13 \%$ & Value of farming as part of community's history and culture \\
\cline { 2 - 3 } & $5 \%$ & Rural character or atmosphere \\
\hline \multirow{5}{*}{ Problems } & $3 \%$ & Other \\
\hline & $67 \%$ & Pesticides spraying \\
\cline { 2 - 3 } & $11 \%$ & Water pollution \\
\cline { 2 - 3 } & $8 \%$ & Air quality, dust, and smells \\
\hline & $8 \%$ & Health problems and uncertainty about health effects \\
\cline { 2 - 3 } & $6 \%$ & Other \\
\hline
\end{tabular}

living near agriculture, including access to fresh food, employment, urban growth limitation and open space provision. The problems with living near agriculture primarily related to pesticide exposure and its potential health problems, as well as concerns about water and air quality.

Participants rated their own health and the health of their household. The most common response was that the residents' health had remained about the same during the past year. These perceived health ratings significantly related to self-reported health problems in the households. Perceived health ratings also correlated significantly with three of the environmental quality ratings (air quality, pesticides and dust), and ratings of attitudes about living near agriculture. Residents who viewed their health positively were more likely to rate environment quality factors positively, while residents who felt their health was worsening had more negative ratings of these factors and were more likely to view living near agriculture as a problem.

In addition, attitudes about living near agriculture were more negative for households with members who had breathing problems and recurring health problems. Residents who viewed air quality and pesticides as problems were more likely to view living near agriculture as a problem.

These perceived environmental quality and health ratings were compared to the background variables. Longer-term residents had more positive attitudes about living near agriculture. Homeowners were more likely to rate the environmental quality of Oceano as higher and they had more positive ratings of living near agriculture. Residents with higher incomes rated their own health and the health of their households as better.

Proximity to agricultural areas related to the perceived environmental quality and attitudes about living near agriculture. Residents who lived near agricultural areas rated their environmental quality as lower and had less positive attitudes about living near agriculture than those who lived further away from the fields. 25 percent of the residents who lived within a block of agricultural areas had negative views of living near agriculture, while less than 10 percent of the more distant residents had negative views of agriculture. 


\subsection{Health Issues}

The survey contained four sets of questions that asked residents about their household members' health problems during the last year. The questions examined the use of emergency medical care, respiratory or breathing problems, cancer and recurring health problems.

The residents were first asked if any members of their household needed emergency medical care within the last year. The data on emergency medical care was compared to the results of a national study on use of emergency care. The overall pattern of medical diagnoses was similar and the usage per capita was less for Oceano than the national sample.

Secondly, they were asked if anyone in their household experienced respiratory or breathing problems in the last year. The data on respiratory or breathing problems was compared to data from the American Lung Association. The rates of respiratory problems in Oceano were approximately equal to or less than county and statewide estimates.

In the third question residents were asked if anyone in their household had been diagnosed with cancer. Households that had lived in Oceano for more than 10 years were more likely to have a household member with cancer than households with less time in Oceano. However, the overall prevalence of cancer was not significantly higher than Central California norms.

In the final question we asked residents if anyone in their household experienced repeated or recurring problems with a list of six health problems (headaches, skin rashes, stomach aches or nausea, vomiting, physical weakness and excessive sweating). These problems were selected because they are symptoms of acute pesticide exposure. About half (52 percent) of the households had no problems, while the other half of the households had either one problem ( 25 percent) or more than one problem (23 percent).

The experience of recurring health problems in the household did relate to the other health variables. Households with recurring health problems were more likely to use emergency medical care, have respiratory problems and have cancer. The experience of recurring health problems in the household also related to the location of the house. Houses bordering agricultural areas were more likely to have multiple recurring health problems than houses more than two blocks away (32 versus 23 percent).

\section{DISCUSSION}

Living in a community adjacent to agriculture should be a benefit for the residents, and many people who live in Oceano appreciate living near agriculture. The residents rate the environmental quality of their community as relatively high, especially for air quality, traffic and noise that are typical urban environmental problems. The majority of residents view living near agricultural fields as a benefit due to the availability of fresh and cheap food, employment for community residents, preventing increased growth and providing open space and beauty.

However, the residents of Oceano are aware of the problems of living near agriculture. A quarter of the residents listed pesticide exposure as the most important environmental problem facing the community. Almost half of the community rated having agricultural fields near their homes as either a mixed experience or problem. Most of those who thought it was a problem listed pesticide exposure as the main problem. The residents' response is typical of a community exposed to chemical contamination. While most members of the community view the community positively and downplay 
the importance of the chemicals, other parts of the community are highly aware of the problem and search for ways to manage it.

In Oceano, about one-quarter of the residents are highly concerned about the health effects of exposure to agricultural chemicals. This concern is related to negative attitudes toward living near agriculture, perceived environmental quality problems, perceived negative health changes, and the presence of health problems in the household. It is difficult to determine if these concerned residents are over-emphasizing the dangers of pesticide exposure from agriculture. There is no conclusive medical research clearly showing a relationship between pesticide exposure and human health.

This study provides some explanation of the characteristics of the people who are concerned about agricultural pesticide exposure. Attitudes toward living near agriculture in Oceano were related to ratings of air quality and pesticide exposure and beliefs about one's health. The perceived health of the residents, respiratory problems in the household, and the experience of recurring health problems were related to attitudes about agriculture. More recent residents to Oceano and renters were more concerned about pesticides. These new people have less commitment to the existing community, so they may be more willing to view it critically.

People who lived adjacent to the agricultural areas had more negative attitudes toward agriculture, more negative ratings of the community's environmental quality, and were more likely to experience recurring health problems that are related to acute pesticide exposure.

It is not possible to use the results of this community health assessment to conclusively demonstrate a relationship between pesticide exposure and health. The health data does not show unusually high usage of emergency medical care, breathing problems or cancer rates. About a quarter of the residents report multiple symptoms of recurring health problems that are related to pesticide exposure. These health results are a reason for concern, but the link to agricultural practices is not conclusive. Without a definitive research conclusion, the community's uncertainty remains.

\section{IMPLICATIONS}

This study had important implications for city and regional planning. It documented health problems in Oceano, but it could not scientifically demonstrate a link between health problems and pesticide use. The study showed that one-quarter of the residents experience stress about the health effects of living near agriculture. This stress, by itself, is a health problem for the community.

There are a variety of solutions to help mitigate or reduce the potential environmental health problems caused by agriculture at the urban fringe. These solutions can be classified as technical, social, environmental or agricultural. The implementation of these solutions requires the cooperative efforts of community members, community environmental organizations, government agencies and farmers.

Technical solutions are designed to reduce pesticide spray drift at its source. Many of these solutions are part of existing EPA regulations, such as improved spray technology and training of pesticide spray applicators. The use of Integrated Pest Management approaches also reduces the use of pesticides, by replacing their use with biological controls of pests and changing farm practices (Van Driesche, et al., 1987).

Social solutions help promote community empowerment by involving community members in reducing the environmental health problem. For example, farmers could be required to inform the community 
whenever pesticides are being used. Education programs can inform residents how to change their behaviors during these days to reduce their exposure. Environmental solutions create buffers between agricultural areas and community residents. The planting of hedges and the establishment of greenbelts and natural buffer areas can reduce chemical exposure to the residents and enhance the environmental quality of the community. Greenbelts provide many of the benefits of living at the urban fringe, such as open space, access to nature, and growth control.

The final set of solutions focuses on agricultural practices. Agriculture at the urban fringe is more successful if it shifts from traditional to adaptive agricultural practices. Unfortunately, adaptive farming often encourages the shift to fruits and vegetables that may be more pesticide intensive than traditional crops. Farmers at the urban fringe need to reassess their relationship to the neighboring community and try to build positive connections between the community and agriculture. One approach is to shift to sustainable agricultural practices that reduce or eliminate the use of pesticides. Organic farming can be used to create environmental buffers that protect residents from pesticide exposure and build a positive relationship between agriculture and the community.

This new relationship between agriculture and the community is exemplified in the growth of Community Supported Agriculture (CSA) (DeLind, 2003). CSA establishes a more direct and personal relationship between farmers and the community by making community members "shareholders" in the farm's activities. Most CSA farms practice organic farming.

Planners need to be concerned about the possible negative effects of living near agricultural areas. When possible, environmental solutions such as buffers can be used to mitigate problems. When environmental solutions are not available, then planners need to work with community residents, farmers and government organizations to implement alternative solutions.

\section{REFERENCES}

Arcury, T., Quandt, S., and Dearry, A. 2001. "Farm worker pesticide exposure and communitybased participatory research: Rationale and practical applications". Environmental Health Perspectives. 109(3): 429-434.

Council for Agricultural Science and Technology (CAST). 2002. Urban and Agricultural Communities: Opportunities for Common Ground. Ames, lowa: CAST.

Daniels, J., Olshan, A., and Savitz, D. 1997. "Pesticides and childhood cancer". Environmental Health Perspectives. 105(10): 1068-1077.

DeLind, L. 2003. "Considerably more than vegetables, a lot less than community". In J. Adams, ed., Fighting for the Farm (pp. 192-208). Philadelphia: University of Pennsylvania Press.

EPA. "Spray Drift of Pesticides". EPA, December 1999. Available from World Wide Web: (www.epa. gov/pesticides/factsheets/spraydrift).

Fuguitt, G. and Brown, D. 1990. "Residential preferences and population redistribution, 1972-1988". Demography. 27(4): 589-600.

Heimlich, R. and Anderson, W. 2001. Development at the urban fringe and beyond: Impacts on agriculture and rural lands. US Department of Agriculture, Agricultural Economic Report No. 803. 
Johnson, K. 1999. "The rural rebound". Reports on America. 1(3): 1-19.

Johnston, T. and Bryant, C. 1987." Agricultural adaptation: The prospects for sustaining agriculture near cities". In W. Lockeretz, ed., Sustaining Agriculture Near Cities (pp 9-21). Ankeny, lowa: Soil and Water Conservation Society.

Jones, R., Fly, J., Talley, J. and Cordell, H. 2003. "Green migration into rural America: The new frontier of environmentalism?" Society and Natural Resources. 16: 221-238.

Molnar, J. and Duffy, P. 1987. "Urban and suburban residents' perceptions of farmers and agriculture." In W. Lockeretz, ed., Sustaining Agriculture Near Cities (pp 119-132). Ankeny, lowa: Soil and Water Conservation Society.

National Research Council. 2000. The Future Role of Pesticides in US Agriculture. Washington: National Academy Press.

Van Driesche, R., Carlson, J., Ferro, D., and Clark, J. 1987. "Pesticides and suburban agriculture". In W. Lockeretz, ed., Sustaining Agriculture Near Cities (pp 49-63). Ankeny, lowa: Soil and Water Conservation Society. 